\title{
A Plataforma de Dados em Saúde está aí - estamos preparados para ela?
}

Raquel Braga*

A Plataforma de Dados em Saúde (PDS), por muitos de nós já utilizada a título experimental, está prestes a ser concluída e vai possibilitar a consulta dos dados clínicos de qualquer paciente em qualquer ponto do país ou até na Europa, algo que era, até há pouco tempo, uma utopia.

Esta partilha e integração da informação é de enorme utilidade para utentes e profissionais, potenciará ganhos em saúde e facilitará os processos de diagnóstico e de orientação dos doentes. Poderá ainda vir a ser um veículo de melhoria dos registos clínicos, de avaliação e garantia de qualidade dos registos, dos processos de conduta clínica, de detecção do erro médico e de desenvolvimento da investigação.

A complexidade do processo de articulação dos dados clínicos dos pacientes é tal que este projecto é um gigantesco e admirável avanço.

Depois desta declaração de admiração total, devo confessar que, tendo estado em algumas sessões de apresentação deste projecto na Unidade Local de Saúde de Matosinhos (ULSM), onde decorrem ensaios, cresce em mim, qual erva daninha, uma sensação incómoda que se prende com inúmeras questões éticas por resolver.

\section{ACESSO À INFORMAÇÃO POR PARTE DOS PROFISSIONAIS}

Quem está familiarizado com sistemas locais de partilha de informação sabe o quão útil, imediato e esclarecedor é, a partir de qualquer dado identificativo de um doente, sem o seu consentimento ou até sem o seu conhecimento, aceder através do sistema de informação do Centro de Saúde aos dados do Hospital ou viceversa.
Todos nos apercebemos como os nossos próprios processos clínicos, dos nossos colegas ou (des)conhecidos estão ali, disponíveis e vulneráveis, sem qualquer sistema de protecção, para quem os queira consultar ou simplesmente devassar, apesar da obrigação de sigilo médico...

Actualmente, a PDS permite o acesso por parte dos médicos e enfermeiros a dados de todos os doentes do Serviço Nacional de Saúde (SNS), apenas ficando inscrito o nome do profissional que consultou o processo. Essa inscrição pode ser visível ao doente, mas não é fácil imaginar que implicações isso possa trazer: Poderão os profissionais de saúde ser processados por consultarem os processos dos doentes sem a sua autorização? Teremos de a pedir, como se de um consentimento informado verbal ou escrito se tratasse?

Foi-me respondido que estas questões estão resolvidas, uma vez que esta permissividade no acesso a qualquer processo já ocorre em muitos sistemas locais de partilha de informação, nomeadamente na ULSM.

Assumir esta resposta é ampliar um problema já identificado. O Conselho Nacional de Ética para as Ciências da Vida, no seu parecer sobre a informação de saúde e registos informáticos de saúde, ${ }^{1}$ ressalta a necessidade do desenvolvimento de uma responsabilidade ética que respeite os direitos das pessoas que utilizam os serviços de saúde. Recomenda que as aplicações informáticas de registo clínico disponham de mecanismos que permitam o acesso a dados clínicos apenas aos profissionais de saúde com responsabilidade na assistência directa àquela pessoa e que, em caso de acesso indevido aos registo de determinada pessoa, surja um alerta para a inconformidade da pretensão, mantendo-se a possibilidade de acesso, desde que devidamente fundamentadas as razões para aceder nessas circunstâncias e reconfirmadas as senhas pessoais de acesso. ${ }^{1}$ 


\section{RESPONSABILIDADE DE O RESUMO CLÍNICO DOS UTENTES SER DO MÉDICO DE FAMÍLIA}

Este capítulo da PDS, que visa sintetizar a informação mais relevante do utente, pretende aproveitar a «inteligência» do médico de família, quem melhor conhece o doente, para construir o resumo do seu processo clínico. Pretende-se disponibilizar o acesso directo desta informação a outros colegas, bem como ao próprio utente. Não havendo dúvidas que o médico de família é, na generalidade das vezes, o médico mais habilitado para conhecer e integrar todos os dados clínicos do seu doente, inúmeras questões se levantam.

A proposta de elaborar o resumo clínico por códigos da International Classification of Primary Care (ICPC) afigura-se demasiado simplista e pouco exequível. Uma vez que esta classificação é apenas utilizada em Cuidados de Saúde Primários (CSP) e não foi criada para este fim, haverá dificuldades na selecção criteriosa dos códigos que devem ser tidos em conta e na sua utilização e interpretação por leigos e profissionais de saúde que não a dominem.

Para um médico de família é difícil manter a lista de problemas sempre actualizada para todos os utentes, até porque estes, por vezes, desenvolvem episódios de saúde fora dos CSP, ou afluem às consultas de Medicina Geral e Familiar (MGF) de forma descontínua.

Ao contrário da prática hospitalar, em que os registos e contacto com o doente são efectuados habitualmente em tempos distintos, em MGF cada encontro origina um registo, normalmente efectuado no decurso da consulta, sobrando pouco tempo para o seu aperfeiçoamento posterior... Em suma, os registos clínicos são frequentemente verdadeiros documentos de trabalho, em permanente actualização e evolução, com diversas notas pessoais e contextuais, acompanhando o desenvolvimento da história natural das doenças e das pessoas e auxiliando o próprio raciocínio clínico, decorrente de um modelo de relação centrado na pessoa.

A complexidade subjacente a este raciocínio, particularmente no caso dos doentes com morbilidade múltipla, mesmo ultrapassando as dificuldades inerentes ao diagnóstico de cada um dos problemas, não será o simples somatório do que resulta da abordagem dos problemas um a um. ${ }^{2}$ Daí que o conceito do que é um resumo clinico deva ser devidamente repensado, como é por exemplo proposto através do modelo do mapa de problemas. ${ }^{2}$ A priorização dos problemas não é uma tarefa fácil, nunca se encontra concluída, variará ao longo do tempo e deve resultar, em última instância, do confronto entre as preocupações do médico e as preocupações do doente. ${ }^{2}$

Levantam-se também as questões de diagnósticos ou problemas sensíveis para o utente e que este não pretenda ver expostos. Incluem-se nestas questões, entre outras, as dependências, as perturbações do foro mental, as doenças infecto-contagiosas, os problemas relacionais ou da esfera sexual, que podendo ser eliminadas do resumo clínico efectuado pelo médico de família, a pedido expresso do utente, podem vir a ser relevantes.

A utilidade de um resumo que pode ser incompleto ou parcial é portanto diminuta, pois nunca dispensará a colheita de uma anamnese completa, sobretudo em situações de urgência.

\section{ACESSO À INFORMAÇÃO POR PARTE DOS PACIENTES}

Esta questão é particularmente sensível, porque não existe em Portugal experiência de os doentes poderem aceder à sua informação clínica, a não ser através dos médicos (verbal ou escrita). Com o acesso directo aos registos levanta-se novamente a discussão: Os registos são do médico ou do doente? A informação clínica é do médico ou do doente?

Segundo a legislação actual, a informação clínica é do doente (ou do titular), algo que só a ele diz respeito, mas os profissionais de saúde são os seus fiéis depositários, sendo que «a comunicação de dados de saúde é feita por intermédio de médico se o requerente o solicitar». ${ }^{3}$

Esta facilitação da informação através da PDS retira em parte a necessidade da sua solicitação por parte do doente, «obrigando» (?) à permanente depuração dos registos clínicos, tendo em conta não só a relevância dos problemas a apresentar como a vontade do doente em os tornar acessíveis. Recomenda-se extremo cuidado na elaboração dos registos clínicos, sobretudo relativamente a fragmentos que, não dizendo respeito ao utente, resultam de inscrições auxiliadoras ao raciocínio médico e à sua memória pessoal e que se podem tornar inadequados ou inúteis como forma de transmissão da informação. 


\section{POSSIBILIDADE DE COLOCAÇÃO DE INFORMAÇÃO NA PDS PELOS PACIENTES}

Partindo do princípio que os diversos médicos que fazem a anamnese do doente, a fazem de forma exaustiva e sistemática, inquirindo toda a informação importante, negando toda a informação necessária e triando a informação realista e útil do ponto de vista médico, que informação relevante para o raciocínio clínico poderá ainda escapar e que seja necessário inscrever pela própria mão do doente?

Não parece útil ou seguro fomentar comunicação para além da crivada através da relação médico-doente, sobretudo se o utente não puder obter confirmação de que a sua informação foi recebida e integrada.

A inscrição de dados pessoais de saúde na PDS pelo doente pode até assumir aspectos potencialmente perigosos, uma vez que estas informações podem ser falsas, incorrectas ou inclusive inscritas por outrem, sem qualquer rigor ou até com segunda intenção.

\section{CONCLUSÃO}

Todos os problemas apontados não afectam a magnitude da obra realizada. É evidente que o processamento da informação foi radicalmente alterado pela utilização dos sistemas de informação e que estes são deveras facilitadores. É mandatório não entravar o progresso nem temer a inovação. Mas, como médicos e fiéis depositários de pedaços da vida e da intimidade dos nossos doentes, devemos salvaguardar o respeito pela informação clínica, pelo sigilo e pela segurança dos sistemas em que inscrevemos a história daqueles que a nós se confiam.

\section{CONFLITO DE INTERESSES}

A autora não tem conflito de interesses.

\section{REFERÊNCIAS BIBLIOGRÁFICAS}

1. Conselho Nacional de Ética para as Ciências da Vida. Parecer $n^{\circ} 60$ do Conselho Nacional de Ética para as Ciências da Vida. Parecer sobre a informação de saúde e registos informáticos de saúde. Disponível em: http://www.cnecv.pt/admin/files/data/docs/1318269169_CNECV\%20 P_60_2011\%2010.10.11.pdf [acedido em 03/02/2013].

2. Broeiro $P$, Ramos V, Barroso R. O mapa de problemas: um instrumento para lidar com a morbilidade múltipla. Rev Port Clin Geral 2007 MarAbr; 23 (2): 209-15.

3. Lei 46/2007, de 24 de Agosto. Diário da República, $n^{\circ} 163$ - 1ª série.

\section{ENDEREÇO PARA CORRESPONDÊNCIA}

director@rpcg.apmcg.pt 